\title{
Aussie facts, EZ-Letters, blue mould, RJR's home page, and UST's "Roar Tour"
}

Web Watch follows issues relevant to tobacco control on the world wide web. The emphasis is on new sites or new features appearing on the web including relevant URLs and short descriptions of the material. $A$ web site is available featuring the URL links referenced in this column; the URL for that site is: <http:// www.gate.net/ jcannon/webwatch/>.

Tobacco in Australia: facts and issues $<h t t p: / / w w w . p e g . a p c . o r g / \sim v s h p />$ Pursuing the objective of bringing about a reduction in death and disease levels due to smoking, the Victorian Smoking and Health Program, Australia (Quit Victoria), has opened the "Tobacco in Australia: facts and issues" web site (figure 1).

"Tobacco in Australia: facts and issues" provides a comprehensive review of the major issues in smoking and health in Australia with all facts and figures fully referenced, and is continually updated by Quit Victoria staff.

Easy-to-follow indices and an excellent search mechanism coupled with a liberal offering of figures and graphs are hallmarks of this site, which may offer the most comprehensive collection of material related to smoking that exists anywhere.

The major categories are: trends in smoking prevalence; trends in tobacco consumption; the health effects of active smoking; the health effects of passive smoking; the Australian cigarette (packaging; constituents; tar, nicotine, and carbon monoxide levels), smoking in the workplace and in public places; taxation and pricing; economic costs and benefits of smoking; smokeless tobacco; uptake of smoking (factors influencing both children and adults); addiction; cessation; anti-smoking campaigns; the tobacco industry in Australia; tobacco advertising; and women and smoking. Much of the research and writing were undertaken by Margaret Winstanley and Stephen Woodward as former employees of Australia's Action on Smoking and Health (ASH), and by Noni Walker, formerly of the Australian Council on Smoking and Health. Financial assistance for the project was provided by the National Campaign Against Drug Abuse (NCADA).

"Tobacco in Australia: facts and issues" is a joint initiative of the Commonwealth Department of Human Services and Health, ASH Australia, Victorian Smoking and Health Program, New South Wales Drug and Alcohol Directorate, and the Health Department of Western Australia.

Web Watch is prepared by fack Cannon. Send correspondence to him by email

(jcannon@gate.net). hundreds of thousands, or even millions of hits to the inquiry? To add insult to injury the search engine then asks: "Here are the first 25 hits. Would you like the next 25 ?" Such "information overload" has the same effect as receiving no information at all.

Recognising this problem, the US Department of Health and Human Services has launched Healthfinder as a gateway consumer health and human services information web site to help people make sense of the stunning amount of information available on the internet. Along with "virtual participant" US Vice President Al Gore, Secretary of Health and Human Services Donna E Shalala launched Healthfinder at the Partnerships '97 conference.

Unlike "Tobacco in Australia: facts and issues", which maintains an online database, Healthfinder provides links that lead to selected online publications, clearing houses, databases, web sites, and support and self-help groups, as well as the government agencies and not-for-profit organisations that produce reliable information for the public.

Healthfinder brings together under one umbrella the broad range of consumer health information resources produced by the federal government and its many partners. Its resources include: links to more than 550 web sites, including more than 200 federal sites and 350 state, local, not-for-profit, university and other consumer health resources; links to nearly 500 selected online documents; links to FAQs (frequently asked questions) on top health issues of concern to the American public; links to databases and web search engines by topic and agency; and graphical and text versions to accommodate all users.

Healthfinder combats "information overload" and endless searches by organising these resources in a subject index, allowing consumers to quickly locate the health information they want. Specific tobacco-related topics $\stackrel{\nabla}{\stackrel{D}{D}}$ available under Healthfinder include: second $\stackrel{\vec{D}}{\mathrm{D}}$ hand smoke; smokeless tobacco; smoking; smoking cessation; and tobacco.

The US Health and Human Services (HHS) agencies included under the Healthfinder umbrella are: Office of the Secretary (OS); $\stackrel{0}{\rightleftharpoons}$ Administration for Children and Families (ACF); Administration on Aging (AOA); Agency for Health Care Policy and Research (AHCPR); Agency for Toxic Substances and

\section{Healthfinder}

<http://www.healthfinder.gov/>

Have you ever used an Internet-based search engine in an attempt to research a specific health-related topic and received thousands,

$$
\text { 옥 }
$$

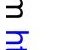




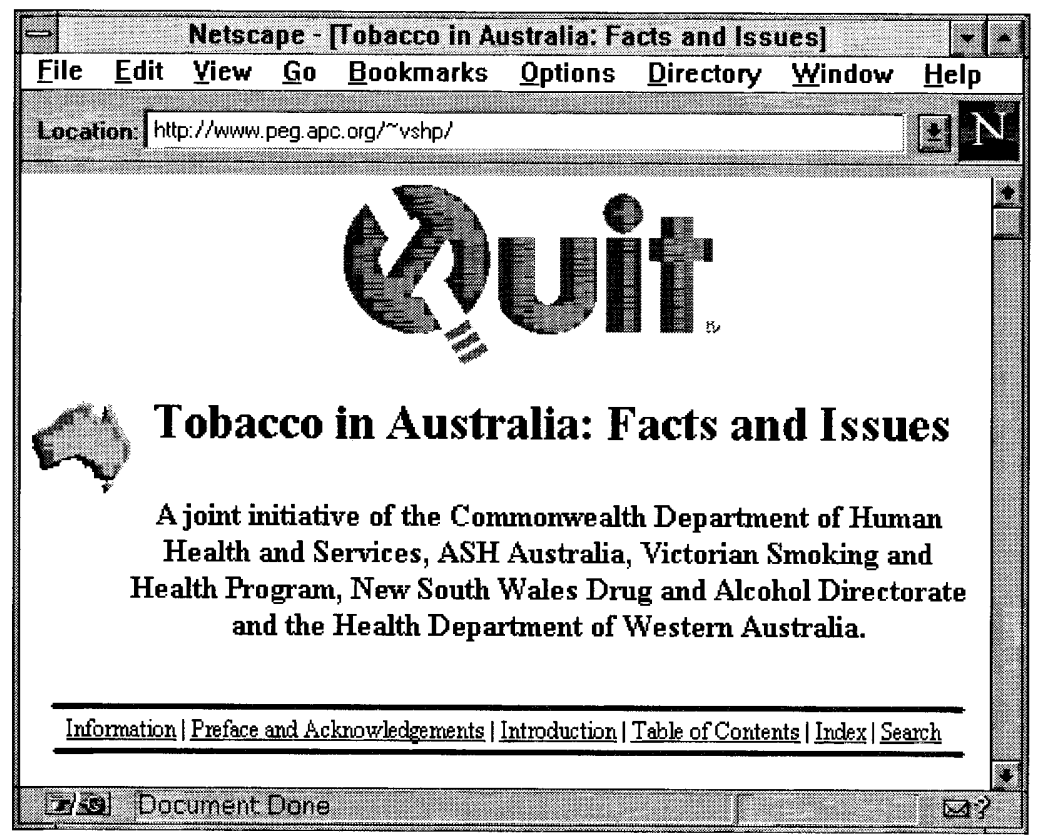

Figure 1 An impressive array of "facts and issues" on tobacco in Australia are covered at this web site.

Disease Registry (ATSDR); Centers for Disease Control and Prevention (CDC); Food and Drug Administration (FDA); Health Care Financing Administration (HCFA); Health Resources and Services Administration (HRSA); Indian Health Service (IHS); National Institutes of Health (NIH); Program Support Center (PSC); and Substance Abuse and Mental Health Services Administration (SAMHSA).

Other federal agencies include: Federal Emergency Management Agency; Library of Congress; Social Security Administration (SSA); Coastguard; Consumer Product Safety Commission; Department of Agriculture; Department of Commerce; Department of Education; Department of Housing and Urban Development; Department of Transportation; Environmental Protection Agency; and General Services Administration.

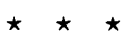

Free home pages for tobacco control groups

Smokescreen Consulting

<http://www.smokescreen.org/>

Unlike traditional home page hosting, which requires learning HTML (hypertext markup language) and a procedure for uploading files to the server, Smokescreen allows organisations to post all their web information via easyto-use forms. The end result is a professional page, complete with a calendar of events, action alerts, job openings, links to other sites, a library of the organisation's files, and a way for users to "subscribe" to the site's page.

The design of Smokescreen is based on the fact that many organisations need exactly the same thing - a calendar of events, an easy way to post action alerts, jobs, files, other links, and a way for members to sign up.

The advantage of having many organisations using the same system is that resources can be more easily shared. A visitor to the site can search through all organisations' events, files, and jobs, without having to visit lots of different web sites and learno different interfaces.

"Very powerful", said Joe Gerner of SmokeFree Educational Services. "I didn't want to spend the money to put afull site on the web, but even as a web novice I had no problem creating a complete site."

$<$ Lttp://www.smokescreen.org/SES/>

Assuming you already have an emilil address and an internet connection, all yougneed to do to post a web presence on Smokescreen is to point your browser to $?<\mathrm{http}: /$ www.smokescreen.org $>$ and click jon Home Page Hosting. You first log yoursaff in as an individual, then click on "Create N $\mathrm{g}$ w Organization". Everything is added. through easy-to-use forms.

in

As of early July, Smokescreen was hosting the web sites of 86 tobaeco control organisations.

EZ-LETTERS

The most powerful feature on the site is EZ-Letters, which has provided cit ens a way to write more than 500 letters over the past few months.

e

Smokescreen provides an easy way for people to channel their energies to oddress the injustices inflicted by tobacco comp tors to Smokescreen's site are presented with situations and sample letters. Wh a few mouse clicks, a sample letter is prepared and is easily customised before a final click kends it (via fax) to the appropriate recipient.

As of July, Smokescreen Consult ter forms available on 17 different issues for seven organisations.

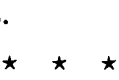

\section{Larry Breed's online guide to toßacco} activism

<http://www.tobacco.org/Resources/lbgơ $i d e . h t m l>$ Get up to speed on the tobacco issue with Larry Breed's terrific, ever-fascinafing, comprehensive guide to agriculturalo business, health, and activist sites.

Available on Gene Borio's Tobacc B BS web site <www.tobacco.org>

\section{Waiting to inhale ${ }^{\star} \star \star \quad$ ก}

<http://www. discovery.com/doc/1012/\%world/

history/cigarettes/cigarettesopener.html

Interested in the history of tob figco? The Discovery Channel has produced a site depicting the noxious weed's history.

Five time segments are $\mathbb{\Phi}$ tegorised: 1850-1900, 1900-19, 1920-50, 1950-64, 1964-77.

The vintage graphics are uriaue and particularly eye-catching. A real कुonus for those meeting the machine requarementsvideo and audio clips!

\section{The costs of smoking $<$ http://www.pioneerplanet.com/archivet/tobac/ smoke/smoke.htm>}

From Knight Ridder's St Paul Pioneer Press, a study on the costs of smoking, including cigarette trends and how much people smoke. 


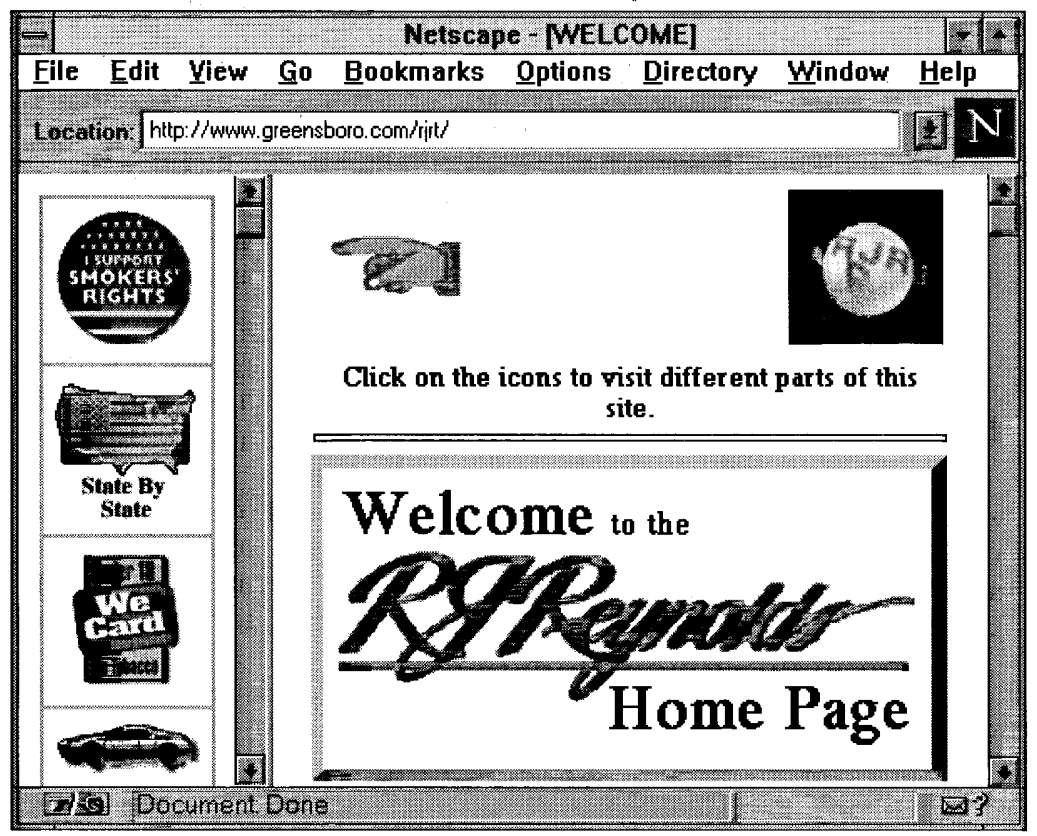

Figure 2 RF Reynolds' new web site, perhaps the tobacco industry's boldest move on the internet to date.

Bar charts are included depicting costs in various countries.

\section{$\star \star \star$}

\section{Liggett documents online}

<http://www.gate.net/ jcannon/liggett/>

An online collection of some of the Liggett documents sealed by Judge William $\mathrm{H}$ Freeman of Forsyth Superior Court in North Carolina are available. Judge Freeman claimed that tobacco companies "could be irreparably harmed" if the secret documents were released.

\section{North America blue mould forecast}

<http://www.ces.ncsu.edu/depts/pp/bluemold/> Blue mould is a local, regional, and continental problem for tobacco farmers. Inoculum (fungus spores) produced in one zone of the North American continent can quickly be transported via the atmosphere to other production areas far distant.

Timely information on the occurrence of blue mould and the future movement of inoculum in the North American continent is important to tobacco producers in managing this destructive and fast-moving plant disease epidemic.

The North Carolina State University of Plant Pathology department and the Marine, Earth, and Atmospheric Sciences department are hosting a blue mould forecast home page. The forecasts represent estimates of pathways spores are likely to travel from confirmed sources via airborne transport. During the 1996 season, 345 forecasts were made on 66 separate days from March through August.

Background information is also provided on: (a) blue mould, the disease; biology, symptoms, diagnosis, etc. (with photos); (b) how the blue mould forecast system works; and (c) weather factors evaluated in creating the forecasts.

\section{RJ Reynolds}

Rf Reynolds home page

$<h t t p: / / w w w . g r e e n s b o r o . c o m / r j r t />$

In what may be the tobacco industry's boldest move on the Internet, RJ Reynolds has opened a site to address issues facing the American tobacco industry (figure 2 ).

BREAKING NEWS

Highlighting this section as we go to press is the tobacco industry response to the Greensboro, North Carolina decision by Judge Osteen affecting FDA regulation of cigarettes and smokeless tobacco products as drugdelivery devices.

\section{RIGHT DECISIONS RIGHT NOW}

This is RJR's youth programme, which they claim is intended to help kids make the right decisions about various activities, including whether to smoke or not to smoke.

True devotees of such material can download their "Right Decisions Right Now" official screensaver. Be prepared to wait, though. It is $500 \mathrm{kB}$. (Does it really make sense to download an executable file provided by a tobacco company?)

SMOKERS' RIGHTS

"When their rights are threatened-through proposed smoking bans, cigarette tax increases, or anti-smoker discriminationthese smokers' rights activists speak out."

One cannot help but wonder if RJ Reynolds is concerned about discrimination against "anti-smokers". However the issue of smoker discrimination does seem to be apparentnowhere on the site does RJR discuss the right of smokers to sue.

TOGETHER WE CAN WORK IT OUT

Always ready to be helpful, RJR will supply their official Workplace Smoking Guides "to help employers and employees develop smoking policies and smoking areas that accommodate the desires of smokers and nonsmokers alike."

SMOKERS FOR A CLEAN AMERICA

This is claimed to be an environmental awareness programme that features disposable ashtrays for smokers 21 years of age of older. One wonders why RJR is ignoring their Joe Camel fans (those under 21).

THE "WE CARD" PROGRAMME

The programme from the Coalition for Responsible Tobacco Retailing to prevent the prosecution of dealers who knowingly sell tobacco products to kids.

\section{Skoal Music "Roar Tour" page}

$<h t t p: / / w w w . r o a r t o u r . c o m />$

In some of their most immoral marketing initiatives to date, conglomerates such as Philip Morris and US Tobacco (UST) have recently teamed up with singers and alternative rock groups to promote cigarettes and smokeless tobacco to teenagers. 
UST is mixing the youthful sounds of alternative rock with the deadly taste of its smokeless tobacco to create a powerful marketing campaign aimed at kids.

The ROAR web page promotes the ROAR LEV, or Lifestyle Experience Village, which promoters are billing as a "multimedia, interactive compound, unprecedented in the history of touring music". It also includes clever enticements to teenagers, such as, "Remember when you were at that party and your best friend embarrassed you in front of that guy or girl you were trying to impress. . . . Bring them to ROAR and challenge them to BOUNCY BOXING, or SUMO WRESTLING. . . ." and "Lots of other cool stuff to be added. And it's all free at ROAR this Summer."

"If there's one sure way to get the attention of youth, it's through alternative rock."-15year-old Anna Markee of Tacoma, Washington.

"Cherry Skoal is for somebody who likes the taste of candy, if you know what I mean."-Former UST sales representative.

\section{Mother Jones}

$<$ http://www. motherjones.com/>

Eric Umansky, editor of Mother fones, has informed me that the magazine is assigning a reporter to Washington, DC, for the purpose of covering possible congressional action on the tobacco industry settlement agreement. Mother fones will be posting a news story on the settlement at least once every two weeks.

News sites dedicated to tobacco issues and maintained by the sponsoring media organisation have proliferated in recent months. Here is a list of the major sites maintaining current tobacco-related news stories.

Washington Post-tobacco main page <http://www.washingtonpost.com/wp-srv/ national/longterm/tobacco/main.htm>

Washington Post - tobacco on trial $<$ http://www.washingtonpost.com/wp-srv/ national/longterm/tobacco/tobacco.htm>

Richmond (Virginia) Times-Dispatch-tobacco page

<http://www.gateway-va.com/pages/news/tobac/ tobacco.htm>

Winston Salem (North Carolina) fournaltobacco page

$<$ http://www.journalnow.com/news/index/ tobacco.shtml>
Winston Salem fournal-tobacco $\frac{\text { settlement }}{\sigma}$ page
sem <http://www.journalnow.com/projects/O tobaccosettlement/>

St Paul (Minnesota) Pioneer Pre弯- tobacco news page

<http://www.pioneerplanet.com/archive $\frac{\overline{0}}{\overline{\bar{p}} / \text { tobac/> }}$

St Paul Pioneer Press-tobacco archiges $<$ http://www.pioneerplanet.com/archiwg/tobac/ $d o x />$

Fort Lauderdale (Florida) Suñz)Sentineltobacco news page <http://sun-sentinel.com/news/tobacco. ̈̊tm > Fort in

Fort Lauderdale Sun-Sentinel-tobacE् editorial cartoons 윽

<http://dynamic.webpoint.com/news/sunsentinel/ gallery/0,1088,5000727,00.html>

Yahoo's tobacco news stories-Reut $\stackrel{\frac{\mathbb{D}}{8}}{\mathrm{D}}$ news services, press releases <http://biz.yahoo.com/news/tobacco.htm

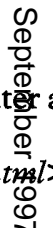

USA Today-smoking and health page $<$ http://167.8.29.8/life/health/smoking lhsmo000.htm>

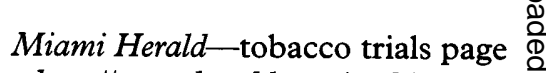
<http://www.herald.com/archive/tobac $\in$ />

New York Times - smoking and heath stories, "Your Health Daily" <http://nytsyn.com/live/Smoking/>

Wall Street fournal-tobacco page <http://interactive6. wsj.com/edition/cu官ent/ summaries/tobacco.htm>

Cable News Network (CNN)-sm产king and health page ò

<http://cnnplus.cnn.com/consumer/hea解/ smoking/index.html>

CNN-tobacco under attack page $\stackrel{\text { D }}{=}$

<http://www.cnn.com/US/9705/tobaccos >

CNN <http://cnn.com/>

The URL for CNN's "Tobacc్ under attack" page changes periodically. It may be best to go to the CNN main page and look for "Focus: tobacco under attack", usu@illy found in a section entitled "SPECIALs". 